\title{
Comparative Anatomy of OS Coxae in Guinea Fowl and Pigeon
}

\author{
C. Lavanya*, S. Jayachitra, K. Iniyah and K. Balasundaram \\ Department of Veterinary Anatomy, Veterinary College and Research Institute, \\ Namakkal, Tanuvas - 637 002, India \\ *Corresponding author
}

\begin{tabular}{|c|c|}
\hline & A B S T R A C T \\
\hline $\begin{array}{l}\text { Guinea fowl, } \\
\text { Pigeon, } \\
\text { Os coxae, } \\
\text { Comparative } \\
\text { Anatomy. }\end{array}$ & \multirow{3}{*}{$\begin{array}{l}\text { The os coxae was collected from guinea fowl and pigeon by wet maceration } \\
\text { method to study the gross anatomical features. The os coxae was formed by } \\
\text { ilium, ischium and pubis, they were fused together and located on either } \\
\text { side of the lumbo sacral mass. The major differences in os coxae of pigeon } \\
\text { were incomplete canales ilioneurales, dorsal median ridge was formed by } \\
\text { spinous process of lumbo sacral mass, absence of pectineal process and all } \\
\text { the three bones were involved in the formation of acetabulum whereas in } \\
\text { guinea fowl the canales ilioneurales was complete, dorsal ridge was formed } \\
\text { only by pre acetabular part of ilium, pectineal process was present and only } \\
\text { ilium and ischium formed the acetabulum. }\end{array}$} \\
\hline Article Info & \\
\hline $\begin{array}{l}\text { Accepted: } \\
\text { 10 July } 2017 \\
\text { Available Online: } \\
\text { 10 September } 2017\end{array}$ & \\
\hline
\end{tabular}

\section{Introduction}

The common helmeted guinea fowl is a domesticated terrestrial bird raised for food purpose and also as pets. They are very good runners, but able to fly for short distances. The common domesticated rock pigeons are gregarious flying birds reared as pets, carrier birds, game birds and for food purpose.

Most of the functional morphologists work at subcellular level, whereas investigation of whole organism is needed to explore the details regarding locomotion of the animals. In birds, especially the fore limb bones are studied in depth towards the functional aspects of flight. However, anatomy of hind limb of birds acquires more importance because of certain features of hind limbs are considered as taxonomic characters (Cracaft, 1971). The os coxae is large and broad to provide greater surface area for the insertion of muscles and to bear the bulk of body weight. The pelvic bones of birds are fused together on each side, between which the vertebral column is wedged. The large size of the pelvic girdle is related to the bipedal standing posture, also the ventrally opened pelvis forms a roof like covering for large part of body cavity and organs contained in it (Mehta et al., 2014). The information on comparative anatomy of os coxae of guinea 
fowl and pigeon was not available. Hence the present study was conducted.

\section{Materials and Methods}

The os coxae of guinea fowl and pigeon with its muscles were collected at Department of Veterinary Pathology during post mortem examination. All the pelvic muscles attached to the bones were removed by blunt dissection. Afterwards the specimens were macerated by wet method of maceration with potassium hydroxide flakes (Raghavan, 1964). Then the collected bones were cleaned by treating with sodium bicarbonate. Various gross morphological features of os coxae were compared between guinea fowl and pigeon.

\section{Results and Discussion}

The os coxae of guinea fowl and pigeon consisted of three bones; ilium, ischium and pubis. The space between the pelvic bones was occupied by rhomboid shaped lumbosacral mass (Mc Lelland, 1990).

\section{Ilium}

In guinea fowl, the ilium was elongated in shape and divided into pre acetabular and post acetabular part and both were joined with the lumbosacral mass. Cranially, the pre acetabular part was completely fused with the dorsal spinous processes of lumbosacral mass and also with its fellow to form an osseus ridge. Thus the fusion of cranial part of the ilium with the spinous processes formed the canales ilio neurales anteriorly (Fig. 1). Mehta et al., (2014) also mentioned that the ilium consisted of pre and post acetabular parts and were fused with lumbosacral mass in Japanese quail. In contrast, the anterior part of the ilium was not fused with dorsal spines of lumbosacral mass so that dorsally opened narrow canales ilioneurales was noticed in pigeon. In guinea fowl, the bony ridge formed was noticed only in the anterior part and it disappeared backwards and was seen as narrow groove. But in pigeon, the bony ridge was formed only by dorsal spinous processes and was present throughout the length of the lumbosacral mass as a ridge. Sreeranjini et al., (2011) has reported that the ridge extended up to the posterior extremity in peahen. The dorsal surface (gluteal surface) of the pre-acetabular part was concave for the attachment of gluteal muscles in both the species studied.

In guinea fowl, the pre and post acetabular part was clearly demarcated by iliac crest on the dorsal aspect and the dorsal surface of post-acetabular part appeared convex. Anteriorly, the ventral surface of the ilium was flat and fused with the transverse process of lumbosacral mass. Posteriorly, it was formed into a depression, iliac fossa or renal fossa for the lodgement of kidney. But in pigeon, the ridge which separated the pre and post acetabular part was not prominent. The gluteal surface was shallow. Iliac fossa on the ventral aspect was wide and shallow (Mehta et al., 2014). As observed by Sathyamoorthy et al., (2012) in spot-billed pelicans and Nickel et al., (1977) in domestic fowl, the dorsal surface of ilium presented a distinct caudal process at its caudal aspect in guinea fowl (Fig. 2).

Whereas in pigeon, the caudal process of ilium was situated more laterally than in guinea fowl due to the wider lumbosacral mass wedged between the two pelvic bones. Mehta et al., (2014) and Sreeranjini et al., (2011) has not mentioned the caudal process at the caudal end of the ilium in Japanese quail and peahen respectively.

\section{Ischium}

The ischium was flat and lies below and lateral to the post acetabular part of ilium in both the species. The ischium was directed 
downwards and backwards in guinea fowl as in domestic fowl (Mc Lelland, 1990). In pigeon, the ischium was fused with the ilium at a wide angle and it was directed outward, downward and backward. As reported by
Nickel et al., (1977) in domestic fowl, the ischium along with the ilium formed the sciatic foramen posterior to the acetabulum in both the species.

Fig.1 Dorsal view of Os coxae of guinea fowl and pigeon

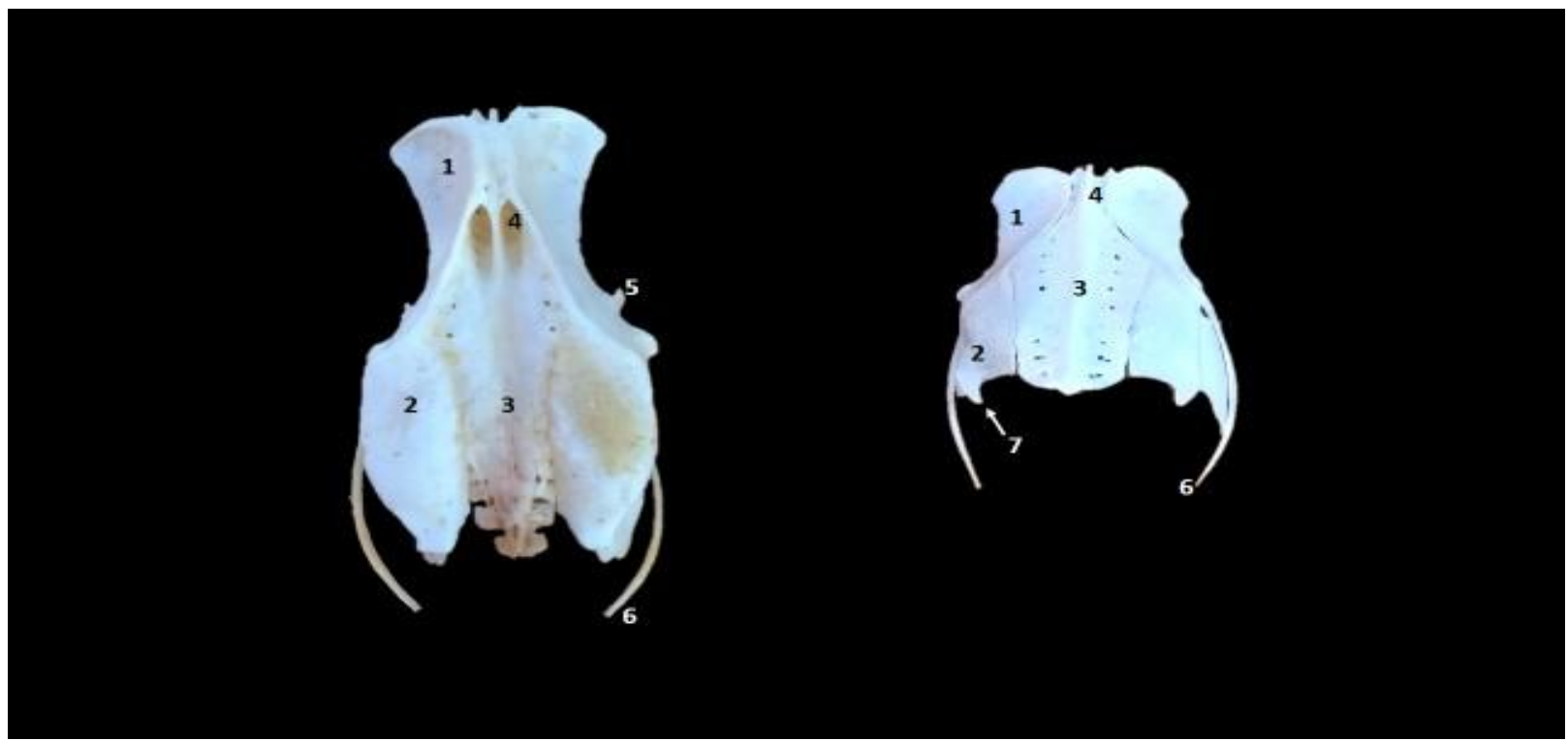

1. Pre acetabular part of ilium, 2. Ischium, 3. Lumbo sacral mass, 4. Canales ilioneurales, 5. Pectineal process, 6. Pubis, 7. Caudal process

Fig.2 Ventral view of Os coxae of guinea fowl and pigeon

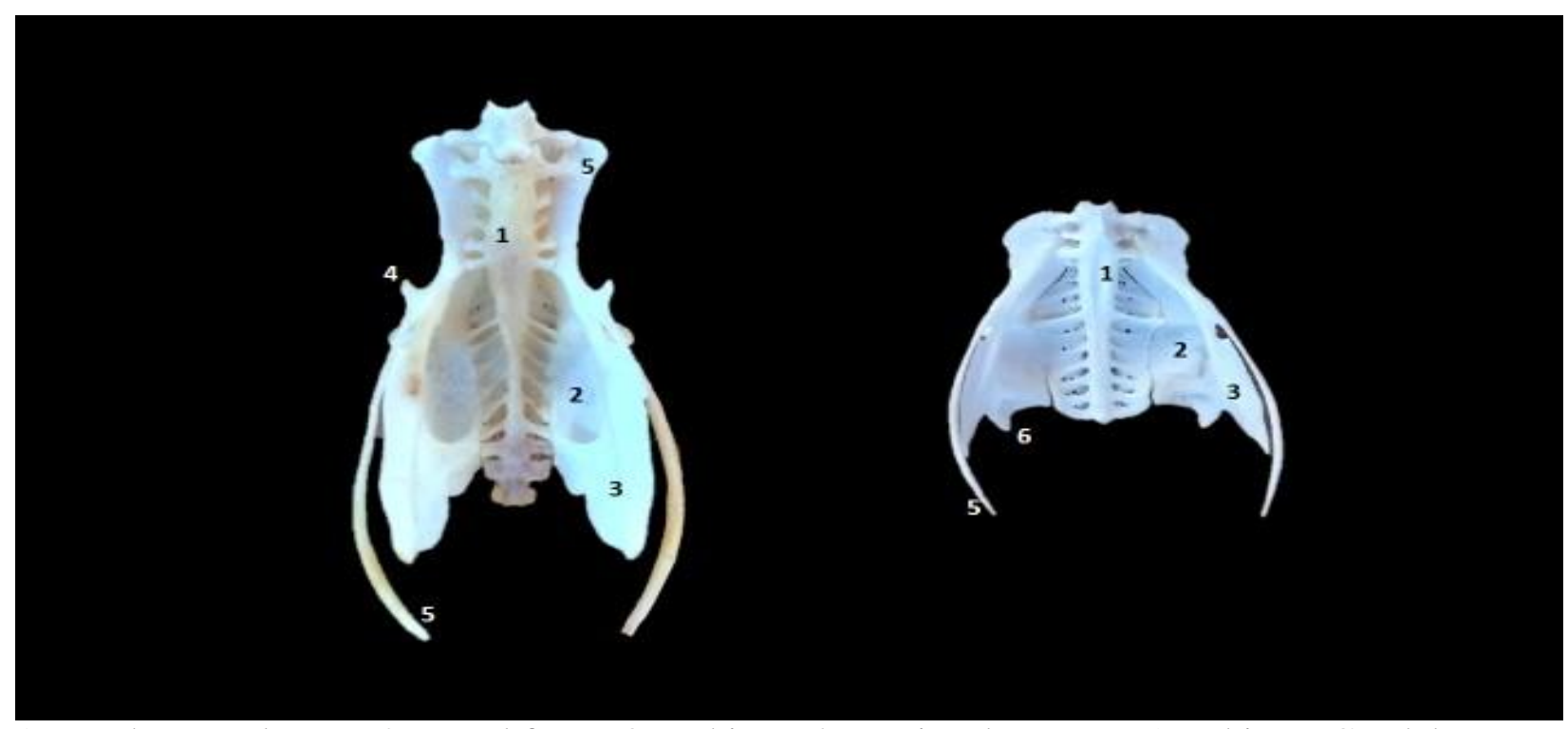

1. Lumbo sacral mass, 2. Renal fossa, 3. Ischium, 4. Pectineal process, 5. Pubis, 6. Caudal process 
Fig.3 Lateral view of Os coxae of guinea fowl and pigeon

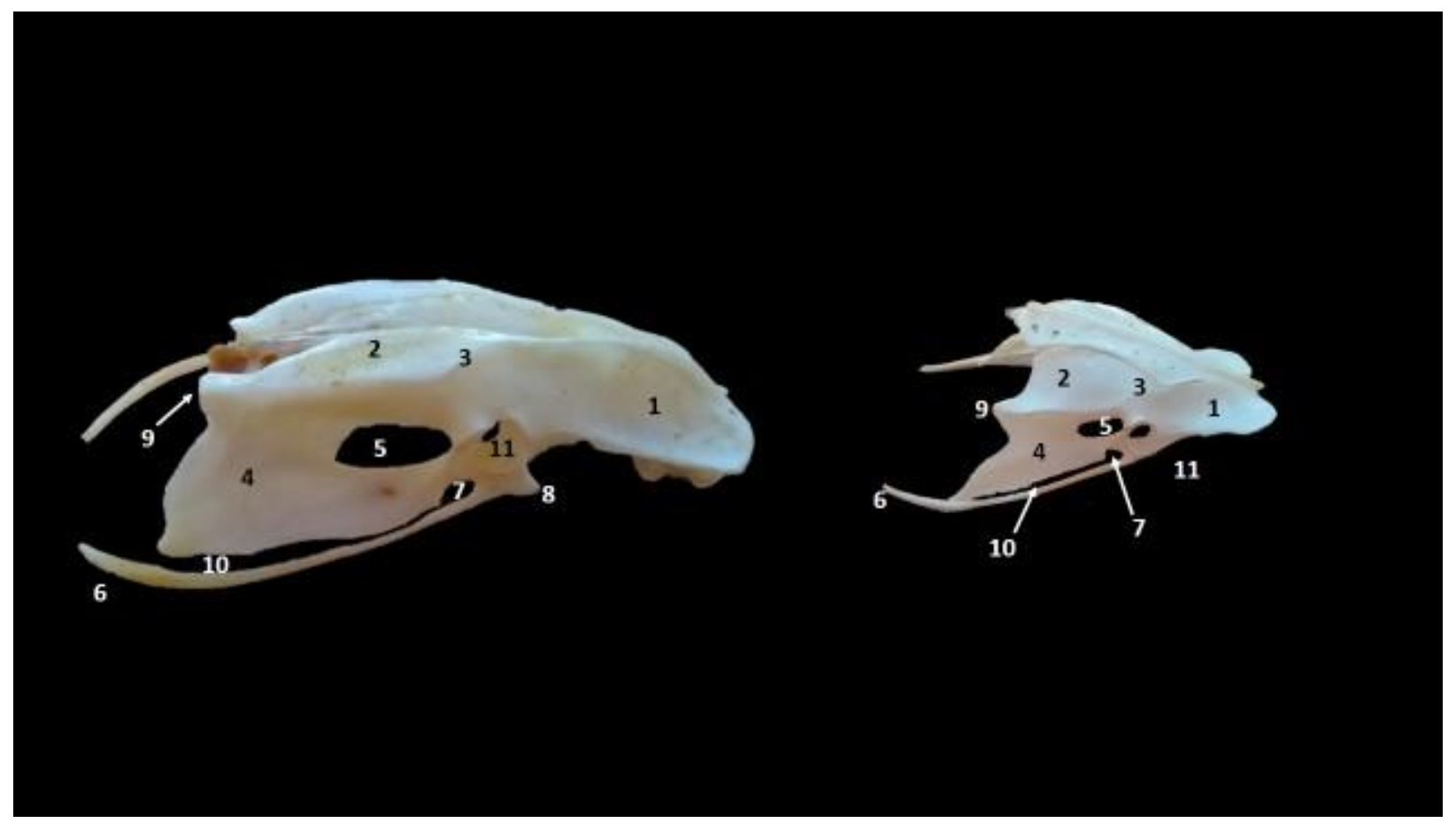

1. Pre acetabular part of ilium, 2. Post acetabular part of ilium, 3.Iliac crest, 4.Ischium, 5.Foramen ischiadicum, 6.Pubis, 7.Obturator foramen, 8.Pectineal process, 9.Caudal process, 10.Ischio - pubic inscisure, 11.Acetabulum

Ventral border of the ischium anteriorly joined with pubis and formed the obturator foramen and continued behind as a fissure in both the species as observed in domestic fowl and duck by Nickel et al., (1977). Posterior border of the ischium was free. The posterior angle of the ischium was blunt ended in guinea fowl and was seen as sharp process in pigeon. But Nickel et al., (1977) reported that the caudal border of the pelvis is formed by ilium and ischium and the projection was located ventrally from this border as angulus ischiadicus in domestic fowl.

\section{Pubis}

The pubis was a thin bony rod situated along the ventral border of ischium and projected further backwards. The ischio - pubic incisure was formed between the ventral border of ischium and dorsal border of pubis. Anteriorly, the ischio - pubic incisure was continued with the obturator foramen in both the species. A small pectineal process was noticed at the anterior end of the pubis below the level of acetabulum in guinea fowl as noted in peahen (Sreeranjini et al., 2011) and domestic fowl (Nickel et al., 1977) and there was no pectineal process seen in pigeon as reported by Mehta et al., (2014) in Japanese quail.

\section{Acetabulum}

As observed by Raghavan, (1964) in cattle, acetabulum was a cotyloid cavity formed by ilium, ischium and pubis and it was like a bony ring with large opening for articulation with the head of the femur in pigeon. But in guinea fowl, the pubis has not contributed to the formation of acetabulum (Fig.3). Nickel et al., (1977) also reported that the ilium and ischium only involved in the formation of cotyloid cavity in domestic fowl and duck. At 
the posteriodorsal aspect of acetabulum a bony prominence, anti trochanter was noticed. A facet was noticed on the anti trochanter for articulation with the trochanter major of femur as mentioned by Sathymoorthy et al., (2012) in spot-billed pelicans and Resk (2015) in cattle egret.

In conclusion the comparative anatomy of os coxae in guinea fowl and pigeon revealed that the os coxae was formed by ilium, ischium and pubis, and it showed minor differences between two species. It is concluded that the differences in osteological features of os coxae may be due to its flying and terrestrial habits.

\section{References}

Cracaft, J. 1971. The functional morphology of the hind limb of domestic pigeon, Columba livia. Bulletin of the American museum of natural history, 144(2).

Mc Lelland, J. 1990. A Colour Atlas of Avian Anatomy, Wolf Publishing Ltd., England.
Mehta, S., Guha, K., Shalini, S. and Kumar, C. 2014. Gross anatomical studies on the os coxae and synsacrum of Japanese quail. Ind. J. Vet. Anat., 26(2): 126 127.

Nickel, R., Schumer, A. and Seiferle, E. 1977. Anatomy of domestic birds, Berlim: Hamburg.

Raghavan, D. 1964. Anatomy of Ox. Indian Council of Agricultural Research, New Delhi.

Resk, H.M. 2015. Anatomical investigation on the appendicular skeleton of the Cattle egret (Bubulcus ibis) J. Exp. Clin. Anat., 14(1): 5-12.

Sathyamoorthy, O.R., Thirumurugan. R., Kumar, K.S. and Jayathangaraj, M.G. 2012. Gross morphological studies on the pelvic girdle of spot-billed pelicans (Pelecanus philippensis). Ind. J. Vet. Anat., 24: 109-110.

Sreeranjini, A.R., Ashok, N., Indu, V.R., Lucy, K.M., Syam, K.V., Chungath, J.J. and Harshan, K.R. 2011. Morphological studies on the pelvic girdle of a peahen. J. Ind. Vet. Assoc. Kerala, 9: 46.

\section{How to cite this article:}

Lavanya, C., S. Jayachitra, K. Iniyah and K. Balasundaram. 2017. Comparative Anatomy of OS Coxae in Guinea Fowl and Pigeon. Int.J.Curr.Microbiol.App.Sci. 6(9): 3655-3659. doi: https://doi.org/10.20546/ijcmas.2017.609.449 